\title{
Editorial:
}

\section{Seguimos Necesitando a Paulo Freire}

\author{
We Still Need Paulo Freire
}

\author{
F. Javier Murillo ${ }^{1 *}$ \\ Cynthia Duk ${ }^{2}$ \\ ${ }^{1}$ Universidad Autónoma de Madrid, España \\ ${ }^{2}$ Universidad Central de Chile, Chile
}

Paulo Freire ha marcado tanto nuestra forma de ver la educación, de ver la vida, que nos ha sido imposible resistir la tentación de dedicarle unas pocas palabras, en este año que celebramos el centenario de su nacimiento. Sin embargo, se han dicho tantas cosas y de forma tan acertada que difícilmente podemos aportar algo mínimamente original. Quizá tampoco lo pretendamos, apenas unas líneas para recordarlo. De entre la multitud de ideas inspiradoras que nos ha legado vamos a centrarnos en tres. Sirva como humilde homenaje.

La esperanza es la primera idea que queremos destacar, tan importante para Freire que tituló "Pedagogía de la Esperanza" uno de sus últimos libros (Freire, 1992). Esperanza sin la cual nuestro trabajo deja de tener sentido; esperanza como necesidad vital de todo ser humano. Esperanza en una sociedad mejor, más justa, más solidaria, más democrática, más inclusiva. Freire nos decía que "sin esperanza no podemos ni empezar a hablar de educación”; pero -seguía- "no cualquier esperanza, una esperanza crítica” (Freire, 1992, p. 8).

Esperanza crítica frente a otras esperanzas que hay que desenmascarar (Murillo y Hernández, 2015): la esperanza ingenua que genera la falsa expectativa de que "las cosas van a mejorar" por sí mismas, y nada se hace; la esperanza mítica por la que se considera que son las personas excepcionales, los héroes y heroínas, los que van a cambiar las cosas; y la esperanza diferida, basada en el convencimiento de que la solución es global; se queda en crítica, pero no se avanza hacia la acción transformadora. Frente a ello, una esperanza crítica que parta del conocimiento de la realidad y la reflexión y que lleve a la acción transformadora.

Freire nos decía: "Mi esperanza es necesaria pero no es suficiente. Ella sola no gana la lucha, pero sin ella la fuerza flaquea y titubea. Necesitamos la esperanza crítica como el pez que necesita el agua incontaminada" (Freire, 1992, p. 8).

La esperanza crítica en educación ha de ser un proceso de profunda reflexión sobre nuestras acciones, nuestras concepciones y los imaginarios sociales que poseemos. Necesitamos romper el círculo vicioso entre la culpa y la inocencia acerca de las dificultades de aprendizaje de las y los estudiantes; hay que ser conscientes de las suposiciones "trampa", de las verdades que no se ponen en duda, de los engaños prescriptivos, de los prejuicios y de los hábitos incuestionados. Y, como nos decía Smyth (2011), solo es posible romper estas trampas con un proceso de formación, reflexión y acción, a partir de la idea del docente como intelectual crítico.

*Contacto: javier.murillo@uam.es

ISSN: 0718-7378

www.rinace.net/rlei/ 
La segunda idea, íntimamente ligada a la anterior, es la consideración de la educación como un acto político. En una entrevista realizada en los primeros titubeos de la recién recuperada democracia española Freire decía:

No hay una dimensión política de la educación, sino que ésta es un acto político en sí
misma. El educador es un político y un artista; lo que no puede ser es un técnico frío.
Ello significa que tiene que tener una cierta opción: la educación para qué, la
educación en favor de quiénes, la educación contra qué. A las clases sociales y
dominantes no les gusta la práctica de una opción orientada hacia la liberación de las
clases dominadas. (Entrevista a Freire por Martín, 1978)

Esta concepción política de la educación nos empodera como educadores y educadoras, nos aporta una dimensión de intelectuales críticos, como decíamos antes. De ahí la necesidad de que nos preguntemos, para qué o para quién trabajamos, a favor de qué intereses... Qué enseñamos, cómo, a quién, para qué o cómo evaluamos, son decisiones políticas, y debemos ser coherentes con ello.

Y hablamos de que la educación es política en sentido freiriano, dado que lleva implícita una concepción de persona y de sociedad. Una sociedad que, para nosotros y apoyándonos también en Freire, es la sociedad democrática, justa e inclusiva, no hay otra.

Y, por último, el énfasis, hoy más necesario que nunca en las personas oprimidas. Para su completa comprensión, nos sirve la propuesta de las "caras de la opresión" de Iris Marion Young (1990) formulada 20 años después de la Pedagogía del Oprimido de Freire (1970), pero que dota a este texto de todo su significado. Young propuso la existencia de cinco caras o tipos de opresión: la explotación, la marginación, la carencia de poder, el imperialismo cultural y la violencia. De ellas, en esta ocasión, nos interesan tres especialmente, la marginación, la carencia de poder y el imperialismo cultural.

Marginación, según Young, es el acto de segregar o confinar a un grupo de personas a una situación social inferior y sustraerlo de los beneficios y el reconocimiento de esa sociedad excluyéndolo. Con ello, marginación es mantener a unas personas o colectivos fuera de los límites de la sociedad, de manera que vivan sin beneficiarse de lo común, con lo que quedan sujetas a un tratamiento paternalista y degradante ante los servicios sociales y las administraciones. Se los excluye de los beneficios de la educación, de la sanidad, de unos servicios urbanos dignos...

La idea de Carencia de Poder, en segundo lugar, constituye otra cara de la opresión de Young. Los-sin-poder están sometidos por la clase dominante, condenados a recibir órdenes y rara vez tienen la opción de decidir sus propias vidas. No participan en los procesos democráticos porque la sociedad siente que no sirve para nada su opinión y no cuenta porque no va a cambiar nada. Con ello, se excluyen de la participación y de cualquier otro proceso de toma de decisiones. También en la educación.

El Imperialismo Cultural, por último, implica adoptar la cultura de la clase dominante como la norma. Los poderosos controlan la información y la interpretación de la sociedad. Difunden los valores, las metas y los intereses de determinados grupos que tienen poder. En este sentido, tienen mucha importancia los medios de comunicación, pero también la educación y el currículo: qué se estudia y cómo implica un modelo de ciudadanía y de la sociedad que se pretende construir. El imperialismo cultural estereotipa a los diferentes y los invisibiliza. Al hacerlo, se define lo que puede y no puede ser. Despersonaliza a los sujetos, convirtiéndolos en una masa sin cara, sin rasgos propios, sin identidad. En el 
análisis de Young, el varón blanco tiene identidad, es un ser único al que se le otorga poder.

Opresión en educación es la segregación escolar, en la que una parte de la sociedad que ostenta el poder excluye y margina a algunas personas a recibir una educación de calidad. Y hablamos de segregación en cualquiera de sus tipologías. Opresión en educación es la falta de democracia en las escuelas, unas escuelas en las que se niega la participación paritaria a muchas personas por su edad, capacidad, pertenencia a grupos minoritarios..., y de hace a través de normas o de facto. Opresión en educación es la imposición de un curriculum homogeneizante, en el que se invisibilizan, excluyen o marginan culturas minoritarias. Creemos que queda todo dicho.

Esperanza crítica, la educación como acto político y la atención a las personas oprimidas, tres ideas de las muchas que nos legó, que queremos recuperar de Freire. Las tres tan actuales que podrían haberse escrito ayer. Gracias Paulo, seguimos necesitándote.

\section{Referencias}

Freire, P. (1970). Pedagogía del oprimido. Siglo XXI.

Freire, P. (1992). Pedagogía de la esperanza. Un reencuentro con la Pedagogía del Oprimido. Siglo XXI.

Martín, K. (1978, 29 de mayo). Paulo Freire: "La educación es siempre un quehacer político". El Pais. https://elpais.com/diario/1978/05/20/sociedad/264463223_850215.html

Murillo, F. J. y Hernández, R. (2015). Esperanza crítica en educación para la justicia social. Revista Internacional de Educación para la Justicia Social, 4(2), 5-9.

Smyth, J. (2011). Critical pedagogy for social justice. Continuum International Publishing Group.

Young, I. M. (1990). Justice and the politics of difference. Princeton University Press. 